\title{
Cytogenetic abnormalities and Y-chromosome microdeletions in infertile Syrian males
}

\author{
WALID AL-ACHKAR, ABDULSAMAD WAFA and FATEN MOASSASS \\ Division of Human Genetics, Department of Molecular Biology and Biotechnology, \\ Atomic Energy Commission of Syria, Damascus, Syria
}

Received July 9, 2012; Accepted August 8, 2012

DOI: $10.3892 /$ br. 2012.40

\begin{abstract}
Infertility is an important health issue affecting numerous couples. Approximately 30-50\% of the cases of male infertility is due to unknown reasons. The main genetic factors involved in male infertility are chromosomal abnormalities and Y chromosome microdeletions within the Yq11 region. The genes controlling spermatogenesis located in the Yq11 region are termed azoospermia factor genes (AZF). Klinefelter syndrome (KS) is the most common of the chromosomal anomalies in the infertile male. AZF microdeletions on the $\mathrm{Y}$ chromosome are the most frequent genetic cause of male infertility. Screening for microdeletions in the $\mathrm{AZFa}, \mathrm{b}$ and $\mathrm{c}$ regions of the $\mathrm{Y}$ chromosome showed a marked variation among different studies. The present study aimed to investigate the prevalence of such deletions in Syrian men. A total of 162 infertile males (97 azoospermic, 49 oligospermic and 16 severely oligospermic) were screened for chromosomal abnormalities and Y chromosome microdeletions using 28 markers in the AZF region. Twenty (12.34\%) patients had chromosomal rearrangements, 17 of them showed sex chromosome abnormalities (11 of 17 patients within the azoospermic group had a KS of $64.7 \%$ ), 2 patients had apparently balanced autosomal rearrangements, while 1 patient had an inversion. Of the 162 infertile men, 46 patients $(28.4 \%)$ had Y chromosome microdeletions within the AZF-regions. Most frequently hit were the AZFc (34.8\%), followed by the AZFbc, AZFa, AZFac, AZFbc, AZFb, AZFd, AZFab, AZFad, AZFbd, AZFabc and the AZFbcd. Combined AZF deletions involving three regions with chromosomal abnormalities were observed in one case. The higher frequency of AZF deletions in our study was comparable with frequen-
\end{abstract}

Correspondence to: Dr Walid Al-Achkar, Division of Human Genetics, Department of Molecular Biology and Biotechnology, Atomic Energy Commission of Syria, P.O. Box 6091, Damascus, Syria

E-mail: ascientific@aec.org.sy

Key words: male infertility, chromosomal aberrations, wide AZF deletions, sequence-tagged site markers, Y chromosome microdeletions cies in other countries and regions of the world, possibly due to the elevated number of the sequence-tagged site (STS) markers used for this screening.

\section{Introduction}

Infertility is an important health problem affecting 10-15\% of couples. The contribution of male factors to infertility is $\sim 30-50 \%$. Previous studies indicated that environmental as well as genetic factors are involved in the decrease of the reproductive potential in male (1). The main genetic factors involved in male infertility are chromosomal abnormalities and Y-chromosomal microdeletions within the Yq11 region. The genes controlling spermatogenesis located in the Yq11 region are termed azoospermia factor genes (AZF) (2).

The incidence of cytogenetic abnormalities has been estimated to be $2.1-28.4 \%$ in infertile men and only $0.7-1 \%$ in the general male population (3). Chromosomal anomalies in the infertile male may be numerical or structural and involve sex chromosomes (e.g., 47,XXY) or autosomes (e.g., balanced Robertsonian translocations) (3). Approximately 5-10\% of the oligozoospermic and $15-20 \%$ of the azoospermic cases harbor genetic abnormalities (4).

Secondary to the Klinefelter syndrome, Y-chromosomal microdeletions are the most frequent genetic cause of male infertility (5). The analysis of these deletions demonstrated four non-overlapping loci, AZFa, AZFb, AZFc and AZFd (5) in the azoosperimic factor gene $(A Z F)$ region. Deletions of these loci result in spermatogenic arrest and are associated with azoospermia or oligozoospermia (5). These AZF genes encode for RNA binding proteins and are likely to be involved in the regulation of gene expression, RNA metabolism, packaging and transport to cytoplasm, as well as RNA splicing (6).

The microdeletion of $\mathrm{AZFa}$ is associated with the complete Sertoli cell-only (SCO) syndrome and azoospermia, while the microdeletion of $\mathrm{AZFb}$ or $\mathrm{AZFc}$ results in a variable clinical and histological phenotype, ranging from the SCO syndrome to oligozoospermia (7). Furthermore, the Y chromosome is of note for its high level of structural variability, including deletions, duplications and inversions (8). Y chromosome polymorphisms, especially a wide range of the length of the sub-band Yq12, were reported to be correlated with reproductive dysfunction (9). It is of note, that microdeletions and chromosomal abnormalities in the AZF region have become 
Table I. Distribution of abnormal karyotypes in infertile patients with non-obstructive azoospermia or oligozoospermia.

\begin{tabular}{llcc}
\hline Abnormalities & \multicolumn{1}{c}{ Abnormal karyotypes } & $\begin{array}{c}\text { Non-obstructive } \\
\text { azoospermia }(\mathrm{n}=97)(\%)\end{array}$ & $\begin{array}{c}\text { Oligozoospermia } \\
(\mathrm{n}=49)(\%)\end{array}$ \\
\hline Sex chromosome & $47, \mathrm{XXY}, 47, \mathrm{XXY}, \mathrm{t}(5 ; 11)(\mathrm{q} 22 ; \mathrm{q} 23)$ & $11(11.37)$ & \\
abnormalities & $47, \mathrm{XXY} / 46, \mathrm{XY}, 45, \mathrm{X} / 46, \mathrm{X}, \mathrm{idic}(\mathrm{Y})(\mathrm{q} 11.21) /$ & $5(5.15)$ & \\
& $47, \mathrm{XX}, \mathrm{idic}(\mathrm{Y})(\mathrm{q} 11.21)$ & & $2(2.04)$ \\
& $46, \mathrm{XY}, \operatorname{der}(\mathrm{X}) \mathrm{t}(\mathrm{X} ; \mathrm{Y})(\mathrm{p} 22.3 ; \mathrm{q} 12)$ & & $2(4.08)$ \\
Autosome abnormalities & $46, \mathrm{XY}, \mathrm{t}(10 ; 18)(\mathrm{q} 25 ; \mathrm{q} 23)$ & $1(1.03)$ & $3(6.12)$ \\
& $46, \mathrm{XY} \operatorname{inv}(9)(\mathrm{p} 12 ; \mathrm{q} 13)$ & $17(17.55)$ & \\
\hline
\end{tabular}

clinically important, since assisted reproductive techniques (ART), such as intracytoplasmic sperm injection (ICSI), have been successfully introduced to clinical treatments (10).

In the present study, the frequency and type of major chromosomal abnormalities including $\mathrm{Y}$ chromosome microdeletions of infertile Syrian men with azoospermia and oligozoospermia were investigated.

\section{Materials and methods}

Patients. Patients were prospectively recruited for chromosomal and Y chromosome microdeletion analysis between 2005 and 2011. A total of 162 infertile Syrian men with non-obstructive azoospermia $(\mathrm{n}=97)$, oligozoospermia $\left(\mathrm{n}=49\right.$, sperm count $\left.<5 \times 10^{6} / \mathrm{ml}\right)$ and severe oligozoospermia ( $\mathrm{n}=16$, sperm count $<1 \times 10^{6} / \mathrm{ml}$ ) aged between 17 and 45 years (the mean \pm SD $32 \pm 7.9$ years) were included in the study. A detailed medical history was recorded for each patient. The patients were also interviewed regarding their medical history, family background, reproductive problems and possible consanguinity with their respective female partners. Physical examination was conducted in order to identify anatomical problems. The urethral fluid and semen were tested for microbial infections, such as mycoplasma infection. In addition, semen analysis was performed, according to the World Health Organization Guidelines (11). A total of 100 healthy men, with proven paternity without assisted reproductive technologies were selected as the controls. None of the patients or controls was exposed to gonadotoxins, such as radiation treatment or cancer chemotherapy.

Cytogenetic analysis. Karyotype analysis using GTG-banding was performed following standard procedures (12). A minimum of 20 metaphases analyzed from stimulated peripheral blood cultures were analyzed for each patient, while in cases with mosaicism this number was increased to 100 metaphases. Karyotypes were described according to the International System for Human Cytogenetic Nomenclature (13).

Molecular analysis. Genomic DNA was extracted from the peripheral blood for the patients and controls, using the Genequality AZF MX kit (AB Analitica, Padova, Italy), according to the manufacturer's instructions. To screen for the $\mathrm{Y}$ chromosome-specific regions, the presence of
28 Y chromosome DNA loci was examined via a sequencetagged site (STS) and genes, mapped in the AZF region. These were distributed on two sets and were found not to overlap. The first set used was included in the Genequality AZF MX kit (AB Analitica), containing 11 specific STS and genes: sY86, sY84, DFFRY and DBY (AZFa); sY95; sY117, sY125, sY127 and sY134 (AZFb); sY254 and sY255 (AZFc), and human zinc-finger protein-encoding genes (ZFX/ZFY) located on the $\mathrm{X}$ - and Y-chromosomes. The ZFX/ZFY and sex determining region of the $Y$ chromosome (SRY, i.e., STS sY14) served as an internal control primer (14). In the second set, the STS primers tested were: sY81 and sY82 (AZFa); sY121, sY124, sY142 and sY143 (AZFb); sY147, sY149, sY158, sY239, sY242, sY283, BPY2, CDY and sY160 (heterochromatin region) (AZFc); sY145 and sY153 (AZFd) $(6,15,16)$. Amplification was carried out in a thermocycler (TC-512; Techne, Staffordshire, UK) under the following conditions: an initial denaturation step at $94^{\circ} \mathrm{C}$ for $5 \mathrm{~min}$, with 40 cycles at $94^{\circ} \mathrm{C}$ for $1 \mathrm{~min}$; annealing at $60^{\circ} \mathrm{C}$ for $1 \mathrm{~min}$ and extension at $72^{\circ} \mathrm{C}$ for $1 \mathrm{~min}$. The final extension step was at $72^{\circ} \mathrm{C}$ for $5 \mathrm{~min}$. The reagents were separated on an ethidium bromide-stained 2.5\% agarose-TAE-gel and observed under UV light.

\section{Results}

Karyotype distribution. Karyotyping was performed for the 100 controls and 162 infertile men with azoospermia $(n=97)$, oligozoospermia $(n=49)$ and severe oligozoospermia $(n=16)$. No chromosome abnormalities were detected in the controls (Table I). Of the $162(12.34 \%)$ infertile patients, 20 had chromosomal abnormalities, including 17 of the 97 (17.52\%) patients with azoospermia and 3 of the $49(6.12 \%)$ patients with oligozoospermia.

Seventeen azoospermic patients presented sex chromosomal abnormalities, accounting for $85 \%$ of the abnormal karyotypes. Approximately 64.7\% (11/17) of these men were born with a 47,XXY karyotype, with the exception of one patient with $47, \mathrm{XXY}, \mathrm{t}(5 ; 11)$, whereas the $29.41 \%$ (5/17) represented patients with $46, \mathrm{XY} / 47, \mathrm{XXY}$ or $45, \mathrm{X} / 46, \mathrm{XY} / 47, \mathrm{XXY}$ mosaicism and $5.9 \%(1 / 17)$ had a $t(X ; Y)$. The remaining 3 patients presented autosomal abnormalities, accounting for $15 \%$ of the abnormal karyotypes. Of the autosomal abnormalities, 2 cases were chromosomal translocations, whereas the other case was inversion. 
Table II. Frequency of different AZF microdeletions on the Y chromosome in infertile male patients $(n=162)$.

\begin{tabular}{|c|c|c|c|c|c|c|c|}
\hline \multirow[b]{2}{*}{ AZF } & \multicolumn{2}{|c|}{$\begin{array}{c}\text { Non-obstructive } \\
\text { azoospermia } \\
(\mathrm{n}=97)(\%)\end{array}$} & \multicolumn{2}{|c|}{$\begin{array}{l}\text { Oligozoospermia } \\
\quad(\mathrm{n}=49)(\%)\end{array}$} & \multicolumn{2}{|c|}{$\begin{array}{c}\text { Sever } \\
\text { ligozoospermia } \\
(\mathrm{n}=16)(\%)\end{array}$} & \multirow[b]{2}{*}{ Total, n $(\%)$} \\
\hline & Set I & Set II & Set I & Set II & Set I & Set II & \\
\hline $\mathrm{AZFa}$ & 3 & 3 & & & & & $6(13.04)$ \\
\hline $\mathrm{AZFb}$ & 1 & & 1 & 1 & & & $3(6.52)$ \\
\hline AZFc & 1 & 10 & & 5 & & & $16(34.8)$ \\
\hline $\mathrm{AZFd}$ & & & & 2 & & 1 & $3(6.52)$ \\
\hline AZFab & 2 & 1 & & & & & $3(6.52)$ \\
\hline AZFac & 1 & 3 & & & & & $4 \quad(8.7)$ \\
\hline AZFad & & 1 & & & & & $1(2.17)$ \\
\hline $\mathrm{AZFbc}$ & 2 & 2 & & 1 & & 2 & $7(15.21)$ \\
\hline AZFbd & & & & 1 & & & $1(2.17)$ \\
\hline AZFabc & & 1 & & & & & $1(2.17)$ \\
\hline AZFbcd & & 1 & & & & & $1(2.17)$ \\
\hline Total deletions n (\%) & & & & & & & \\
\hline
\end{tabular}

Effects of the frequency of AZF microdeletions on $Y$ chromosome. A total of 262 cases, including 162 azoospermia ( $\mathrm{n}=97)$, oligozoospermia $(n=49)$, severe oligozoospermia $(n=16)$ and 100 controls, were analyzed for the incidence of $\mathrm{Y}$ chromosome deletions (Table II). Forty-six cases of 162 (28.4\%) infertile males presented $\mathrm{Y}$ chromosome microdeletions. No microdeletions were detected in the controls. The frequency of microdeletions was 33\% (32/97) in the azoospermic group compared to $22.44 \%$ (11/49) in the oligozoospermic and $18.8 \%$ (3/16) in the severely oligozoospermic group.

In this study, the type of $Y$ chromosome microdeletions analyzed included AZFa, AZFb, AZFc, AZFd, AZFab, AZFac, AZFad, AZFbc, AZFbd, AZFabc and AZFbcd (Table II). Deletion of AZFc was the most frequent AZF microdeletion in azoospermic as well as oligozoospermic patients, present in 16 of 46 (34.8\%) of all AZF microdeletions. Six azoospermic males of 46 patients (13.04\%) presented with deletion in the $\mathrm{AZFa}, 3$ of 46 infertile patients $(6.52 \%)$ in the $\mathrm{AZFb}$ and 3 of 46 infertile patients (6.52\%) in the AZFd region. Only azoospermic patients presented AZFa microdeletions. The larger types of microdeletions involving 2 or 3 complete AZF regions included 7 of 46 infertile patients $(15.21 \%)$ of the AZFbc, 4 of 46 infertile patients (8.7\%) of the AZFac, 1 of 46 infertile patients (2.17\%) of the AZFabc and 1 of 46 infertile patients (2.17\%) of the AZFbcd regions, respectively.

Combined deletions involving the three AZF regions $(b$, c and d) were detected in 1 patient with $45, \mathrm{X} / 46, \mathrm{X}, \operatorname{idic}(\mathrm{Y})$ (q11.21)/47,XX,+idic(Y)(q11.21), while the molecular analysis of the SRY gene showed the presence of 2 copies of this gene.

\section{Discussion}

Chromosomal abnormalities are more frequently observed in azoospermic and oligospermic patients compared to the general population (17). In the present study, the total prevalence of chromosomal aberrations was $12.34 \%$, in accordance with the previously reported rates of $2.2-14.3 \%$ for infertile men $(18,19)$. The most common chromosomal abnormality was the Klinefelter syndrome, accounting for $64.7 \%$ (11/17) of the detected chromosomal abnormalities, followed by mosaic Klinefelter syndrome and structural autosomal abnormalities. The incidence of sex chromosomal abnormality in men with azoospermia (16.5\%) was higher compared to men with oligozoospermia (2.04\%), largely due to the high incidence of patients with Klinefelter syndrome. The incidence of autosomal abnormalities in infertile patients with azoospermia was $(1.03 \%)$ and $(4.08 \%)$ in patients with oligozoospermia. The majority of autosomal abnormalities in the infertile population were chromosome translocation, potentially inducing the loss of genetic material at the breakpoints of genes and corrupting the genetic message (20). Findings of the present study are consistent with the finding that abnormalities in sex chromosomes are primarily found in azoospermic patients, while balanced autosomal abnormalities are the most frequent abnormalities in oligozoospermic males (21).

The reported frequencies of deletions in the AZF region vary from 1 to $55 \%$, depending on the inclusion criteria and possibly on the STS markers used for screening, however, mostly an incidence below $15 \%$ is reported $(22,23)$.In this study, 11 STS markers, including 6 STS strongly recommended by the European Molecular Genetics Quality Network (EMQN) and the European Academy of Andrology (EAA) guidelines, were used (14). This method has been considered as relatively reliable to identify $90 \%$ of AZF microdeletions and has been widely employed in many laboratories. Consistent with the literature, in the present study the observed frequency of deletions was $6.8 \%$ (14). However, the use of more primers-sets, compared to those used in this study, improves the chances of finding a deletion $(24,25)$. When using an additional 17 STS markers, further deletions were detected within the AZF 
regions. Overall, the observed frequency was $21.6 \%$. Thus, consistent with other reports in the literature (22), the observed frequency of AZF-microdeletions was $28.4 \%$. However, using that number of STS-markers is not in accordance with the recommendations of the EAA (14).

The frequency of AZF microdeletion was $33 \%$ in patients with azoospermia, $22.44 \%$ in patients with oligozoospermia and $18.8 \%$ in patients with severe oligozoospermia. These results are different from the published data of $10-15 \%$ in azoospermic patients and 5-10\% in oligozoospermic patients (26). However, in a review of the literature (27-29), the authors observed a high frequency $(51.6 \%)$ of microdeletions among azoospermic patients (27). These variations in deletion frequencies could be explained by ethnic or geographical differences, the selection criteria of the patients and the sample size.

According to the literature, among the AZF-genes, AZFc is the most frequently deleted one (60\%), followed by deletions of $\mathrm{AZFb}$ and the combined deletions involving different AZF regions (35\%), whereas AZFa deletions are extremely rare $(5 \%)$ (30). In the present study, microdeletions in the AZFc region were the most prevalent (34.8\%), followed by the AZFbc (15.21\%), AZFa (13.04\%) and AZFac (8.7\%). Thus, the frequency of $\mathrm{AZFa}$ deletions in our sample was higher compared to other reports $(14,31,32)$.

AZF subregions act in different phases of spermatogenesis. The complete deletion of the AZFa region is suggested to result in complete Sertoli cell-only syndrome and azoospermia $(14,33)$. Deletions of the AZFb region may induce SCO syndrome or the arrest of spermatogenesis in the primary spermatocyte stage (34). Deletions in the AZFc region produce a variety of phenotypes ranging from normal to oligozoospermia and azoospermia $(14,35)$.

Deletions in the AZFd are likely to present with mild oligospermia or even normal sperm counts with abnormal sperm morphology, such as severe teratozoospermia phenotype (31). A deletion of the AZFc region may also predispose men to Y chromosome loss, leading to sexual reversal. Several studies have found this deletion to be a premutation for $45, \mathrm{X}$ $(35,36)$ and for the mosaic phenotype 45,X/46,XY (37). Consistent with the results of the present study, AZFa deletions were only detected in azoospermic patients, although $\mathrm{AZFb}, \mathrm{AZFc}$ and $\mathrm{AZFd}$ deletions were found in three groups of patients. In addition, the present study showed that combined deletions involving the three AZF regions, AZFa,b regions or partial $\mathrm{AZFb}$ deletions were also only detected in azoospermic patients.

The combination of chromosomal abnormality and $\mathrm{Y}$ chromosome microdeletion was observed in 1 patient. This patient had 45,X/46,X,idic(Y)/47,XX,+idic(Y) karyotype and AZFbcd (38).

Infertile men are increasingly selecting ART, such as ICSI/ IVF, as a feasible option in order to have their own offspring. With the help of ART, it is possible for patients with severe impaired spermatogenesis to father children. However, these technologies are likely to increase the risk of transmitting their genetic disorder to their descendants. Thus, prior to assisted reproduction, an understanding of the genetic defects for the infertile male is essential to avoid the vertical transmission of anomalies to the offspring.
In summary, the frequencies of AZF microdeletions and chromosomal abnormalities in infertile men from Syria were comparable with those of infertile men from other countries and regions in the world. The results demonstrated a higher prevalence of AZF deletions compared to other studies, suggesting that this increase depends on the number of the STS markers used for screening.

\section{Acknowledgements}

The authors would like to thank Professor I. Othman, the General Director of the Atomic Energy Commission of Syria (AECS) and Dr N. Mirali, Head of the Department of Molecular Biology and Biotechnology, for their support. This study was financed by the Syrian Atomic Energy Commission.

\section{References}

1. Krausz C, Quintana-Murci L and McElreavey K: Prognostic value of Y deletion analysis: what is the clinical prognostic value of Y chromosome microdeletion analysis? Hum Reprod 15: 1431-1434, 2000

2. Vogt P, Chandley AC, Hargreave TB, Keil R, Ma K and Sharkey A: Microdeletions in interval 6 of the Y chromosome of males with idiopathic sterility point to disruption of AZF, a human spermatogenesis gene. Hum Genet 89: 491-496, 1992.

3. Vutyavanich T, Piromlertamorn W, Sirirungsi W and Sirisukkasem S: Frequency of Y chromosome microdeletions and chromosomal abnormalities in infertile Thai men with oligozoospermia and azoospermia. Asian J Androl 9: 68-75, 2007.

4. Dada R, Gupta NP and Kucheria K: Cytogenetic and molecular analysis of male infertility $\mathrm{Y}$ chromosome deletion during nonobstructive azoospermia and severe oligozoospermia. Cell Biochem Biophys 171: 171-177, 2006.

5. Kleiman SE, Yogev L, Gamzu R, Hauser R, Botchan A, Lessing JB, Paz G and Yavetz H: Genetic evaluation of infertile men. Hum Reprod 14: 33-38, 1999.

6. SãoPedro SL, Fraietta R, Spaine D, Porto CS, Srougi M, Cedenho AP and Avellar MC: Prevalence of Y chromosome deletions in a Brazilian population of nonobstructive azoospermic and severely oligozoospermic men. Braz J Med Biol Res 36: 787-793, 2003.

7. Zhou-Cun A, Yang Y, Zhang SZ, Zhang W and Lin L: Chromosomal abnormality and Y chromosome microdeletion in Chinese patients with azoospermia or severe oligozoospermia. Yi Chuan Xue Bao 33: 111-116, 2006.

8. Balaresque P, Bowden GR, Parkin EJ, Omran GA, Heyer E, et al: Dynamic nature of the proximal AZFc region of the human Y chromosome: multiplex independent deletion and duplication events revealed by microsatellite analysis. Hum Mutat 29: 1171-1180, 2008.

9. Fu SB: Medical genetics. In: Chromosomal Disease. 2nd edition. Bu XB (ed). Peking University Medical Press, Beijing, pp63-88, 2009.

10. Devroey P, Fauser BC and Diedrich K: Approaches to improve the diagnosis and management of infertility. Hum Reprod Update 15: 391-408, 2009.

11. World Health Organization: WHO Laboratory Manual for the Examination of Human Semen and Sperm-Cervical Mucus Interaction. 4th edition. Cambridge University Press, Cambridge, 1999.

12. Al-Achkar W, Wafa A, Moassass F and Liehr T: Partial trisomy 9p22 to 9p24.2 in combination with partial monosomy 9pter in a Syrian girl: a case report. Mol Cytogenet 3: 18, 2010.

13. Shaffer L, Slovak M and Cambell L (eds): ISCN (2009): An International System for Human Cytogenetic Nomenclature. S. Karger, Basel, 2009.

14. Simoni M, Bakker E and Krausz C: EAA/EMQN best practice guidelinesfor molecular diagnosis of Y-chromosomal microdeletions. State of art 2004. Int J Androl 27: 240-249, 2004.

15. Balkan M, Tekes S and Gedik A: Cytogenetic and Y chromosome microdeletion screening studies in infertile males with Oligozoospermia and Azoospermia in Southeast Turkey. J Assist Reprod Genet 25: 559-565, 2008. 
16. Mirfakhraie R, Mirzajani F, Kalantar SM, Montazeri M, Salsabili N, Pourmand GR and Houshmand M: High prevalence of $\mathrm{AZFb}$ microdeletion in Iranian patients with idiopathic nonobstructive azoospermia. Indian J Med Res 132: 265-270, 2010.

17. Tuerlings JH, de France HF, Hamers A, Hordijk R, Van Hemel JO, Hansson K, Hoovers JM, Madan K, Van der Blij-Philipsen M, Gerssen-Schoorl KB, Kremer JA and Smeets DF: Chromosome studies in 1792 males prior to intra-cytoplasmic sperm injection: the Dutch experience. Eur J Hum Genet 6: 194-200, 1998.

18. Van Assche E, Bonduelle M, Tournaye H, Joris H, Verheyen G, Devroey P, Van Steirteghem A and Liebaers I: Cytogenetics of infertile men. Hum Reprod 11: 1-24, 1996.

19. Vicdan A, Vicdan K, Günalp S, Kence A, Akarsu C, Işik AZ and Sözen E: Genetic aspects of human male infertility: the frequency of chromosomal abnormalities and Y chromosome microdeletions in severe male factor infertility. Eur J Obstet Gynecol Reprod Biol 117: 49-54, 2004.

20. Carrell DT: Contributions of spermatozoa to embryogenesis: assays to evaluate their genetic and epigenetic fitness. Reprod Biomed Online 16: 474-484, 2008.

21. Elghezal H, Hidar S, Braham R, Denguezli W, Ajina M and Saâd A: Chromosome abnormalities in one thousand infertile males with nonobstructive sperm disorders. Fertil Steril 86: 1792-1795, 2006

22. Fu L, Xiong DK, Ding XP, Li C, Zhang LY, Ding M, Nie SS and Quan Q: Genetic screening for chromosomal abnormalities and Y chromosome microdeletions in Chinese infertile men. J Assist Reprod Genet 29: 521-527, 2012.

23. Hadjkacem-Loukil L, Ayadi I, Bahloul A, Ayadi H and Ammar-Keskes L: Tag STS in the AZF region associated with azoospermia in a Tunisian population. J Androl 28: 652-658, 2007.

24. Thangaraj K, Gupta NJ, Pavani K, Reddy AG, Subramainan S, Rani DS, Ghosh B, Chakravarty B and Singh L: Chromosome deletions in azoospermic men in India. J Androl 24: 588-597, 2003.

25. Mitra A, Dada R, Kumar R, Gupta NP, Kucheria K and Gupta SK: Y chromosome microdeletions in azoospermic patients with Klinefelter's syndrome. Asian J Androl 8: 81-88, 2006.

26. Wang RX, Fu C, Yang YP, Han RR, Dong Y, Dai RL and Liu RZ: Male infertility in China: laboratory finding for AZF microdeletions and chromosomal abnormalities in infertile men from Northeastern China. J Assist Reprod Genet 27: 391-396, 2010.

27. Ali M and Hayat M: Screening of ' $Y$ ' chromosome microdeletions in Iranian infertile males. J Hum Reprod Sci 1: 2-9, 2008.
28. Ferlin A, Arredi B, Speltra E, Cazzadore C, Selice R, Garolla A, Lenzi A and Foresta C: Molecular and clinical characterization of Y chromosome microdeletions in infertile men: a 10-year experience in Italy. J Clin Endocrinol Metab 92: 762-770, 2007.

29. Simoni M, Tuttelmann F, Gromoll J and Nieschlag E: Clinical consequences of microdeletions of the Y chromosome: the extended Münster experience. Reprod Biomed Online 16: 289-303, 2008.

30. Pina-Neto JM, Carrara RC, Bisinella R, Mazzucatto LF, Martins MD, Sartoratto E and Yamasaki R: Somatic cytogenetic and azoospermia factor gene microdeletion studies in infertile men. Braz J Med Biol Res 39: 555-561, 2006.

31. Ceylan GG, Ceylan C and Elyas H: Genetic anomalies in patients with severe oligozoospermia and azoospermia in eastern Turkey: a prospective study. Genet Mol Res 8: 915-922, 2009.

32. Sadeghi-Nejad H and Farrokhi F: Genetics of azoospermia: current knowledge, clinical implications, and future directions. Part II: Y chromosome microdeletions. Urol J 4: 192-206, 2007.

33. Vogt PH, Edelmann A, Kirsch S, Henegariu O, Hirschmann P, Kiesewetter F, Köhn FM, Schill WB, Farah S, Ramos C, et al: Human Y chromosome azoospermia factors (AZF) mapped to different subregions in Yq11. Hum Mol Genet 5: 933-943, 1996.

34. Yang Y, Ma MY, Xiao CY, Li L, Li SW and Zhang SZ: Massive deletion in $\mathrm{AZFb} / \mathrm{b}+\mathrm{c}$ and azoospermia with sertoli cell only and/or maturation arrest. Int J Androl 31: 573-578, 2008.

35. Zhang F, Lu C, Li Z, Xie P, Xia Y, Zhu X, Wu B, Cai X, Wang X, Qian J, et al: Partial deletions are associated with an increased risk of complete deletion in AZFc: a new insight into the role of partial AZFc deletions in male infertility. J Med Genet 44: 437-444, 2007.

36. Jaruzelska J, Korcz A, Wojda A, Jedrzejczak P, Bierla J, Surmacz T, Pawelczyk L, Page DC and Kotecki M: Mosaicism for $45, \mathrm{X}$ cell line may accentuate the severity of spermatogenic defects in men with AZFc deletion. J Med Genet 38: 798-802, 2001.

37. Patsalis PC, Sismani C, Quintana-Murci L, Taleb-Bekkouche F, Krausz C and McElreavey K: Effects of transmission of Y chromosome AZFc deletions. Lancet 360: 1222-1224, 2002.

38. Al-Achkar W, Wafa A, Liehr T, Klein E and Moassass F: Detailed analysis of an $\operatorname{idic}(Y)(q 11.21)$ in a mosaic karyotype. Mol Med Report 6: 293-296, 2012. 